\title{
Skolt Sami Language
}

National Cancer Institute

\section{Source}

National Cancer Institute. Skolt Sami Language. NCI Thesaurus. Code C154123.

A Uralic Sami language that is spoken by the Skolts people in Finland. 